\title{
Estudos de Prospecção sobre Matriz Polimérica para Imobilização de Bactérias e uso em Biorremediação
}

\author{
Prospective Studies on Polymeric Matrix for Bacterial Immobilization \\ and Biorremediation Aplication
}

\author{
Carla Jaqueline Silva Sampaio ${ }^{1}$ \\ Cristina Maria Quintella ${ }^{1}$ \\ Milton Ricardo de Abreu Roque ${ }^{1}$ \\ ${ }^{1}$ Universidade Federal da Bahia, Salvador, BA, Brasil
}

\begin{abstract}
Resumo
A imobilização consiste no aprisionamento físico de compostos ou células em uma matriz imobilizante. Este trabalho tem como objetivo realizar um estudo de prospecção de patentes relacionadas à produção e formulação de matrizes para imobilização de bactérias e aplicação em biorremediação. Realizou-se a prospecção de patentes no banco de dados Espacenet ${ }^{\circledR}$, entre abril e maio de 2018, com as palavras-chave: immobilization, bacterial immobilization $e$ bioremediation. O código C12N11/16 melhor contemplou o objetivo do trabalho, com 303 patentes depositadas. Houve depósito a partir de 1968. Os Estados Unidos possuem 22 patentes e o Brasil apenas 3. Do total, $45 \%$ das patentes são depositadas por pessoa física, $41 \%$ por empresas e apenas $14 \%$ por universidades e institutos. Os códigos encontrados envolvem a formulação de matriz polimérica, imobilização e produção de enzimas e cultivo de microrganismos. Sendo assim, faz-se necessário o desenvolvimento de tecnologias relacionadas a matrizes poliméricas imobilizantes de células bacterianas para aplicação em biorremediação.
\end{abstract}

Palavras-chave: Polímero. Imobilização celular. Biorremediação.

\begin{abstract}
Immobilization consists of the physical entrapment compounds or cells in immobilizing matrix. This work has been a retrospective study of the patents related to production and simulation for bacterial immobilization and application in bioremediation. A patent search was carried out in the database. As of May 2018, with keywords: immobilization, bacterial immobilization and bioremediation. The code C12N11/16 better contemplation of the work, with 303 patents deposited. As a deposit from 1968. The United States has 22 patents and Brazil only 3. Of the total, $45 \%$ are patents per individual, $41 \%$ by companies and only $14 \%$ by universities and institutes. The codes found are a polymer matrix formulation, immobilization and enzyme production and culture of microorganisms. Thus, it is necessary to develop technologies related to bacterial cell immobilizing polymer matrices for bioremediation application.
\end{abstract}

Keywords: Polymer. Cell immobilization. Bioremediation.

Área tecnológica: Microbiologia, Biorremediação, Biomateriais. 


\section{Introdução}

A imobilização celular consiste em um processo de aprisionamento físico das células utilizando uma matriz encapsulante ou imobilizante. A técnica pode ser aplicada para imobilização de substâncias bioativas como imunobiológicos, medicamentos, enzimas e outras biomoléculas. Adicionalmente, a técnica de imobilização é bastante utilizada para a imobilização celular, seja em forma de cápsulas ou membranas, onde há preservação da viabilidade celular (KAREL et al., 1985). Devido à sua ampla versatilidade de utilização, a imobilização é utilizada por indústrias de alimentos, biotecnologia, farmacêutica e ambiental (PEINADO et al., 2005).

A matriz encapsulante, geralmente constituída por um polímero, é semipermeável e permite a entrada de substâncias como nutrientes e oxigênio, assim como a saída do material encapsulado. A permeabilidade da matriz impede que moléculas com elevado peso molecular adentrem a cápsula, preservando a integridade do material encapsulado, além de constituir uma fonte de carbono e energia para a manutenção do metabolismo das células aprisionadas (ORIVE et al., 2004) .

Algumas características são essenciais para uma matriz encapsulante, tais como: insolubilidade, não biodegradável, não tóxico, não poluente, peso leve, flexibilidade, alta estabilidade mecânica, química e biológica, alta difusividade, simples procedimento de imobilização, alta retenção de biomassa, tamanho e formas adequados, longa duração em prateleira e baixo custo (BAYAT et al., 2015; MARTINS et al., 2013) .

A imobilização de células através da técnica de encapsulamento tem adquirido avanços nas distintas áreas do conhecimento como biotecnologia, agricultura, farmacêutica e biorremediação (ELNASHAR, 2010). A técnica de imobilização de células por encapsulamento permite que haja aumento da biomassa, proteção e estabilidade, características essenciais para a resistência dos microrganismos em ambientes inóspitos (BAYAT et al., 2015; WASI et al., 2013) .

Os microrganismos imobilizados constituem uma importante ferramenta na descontaminação de ambientes. Assim como os microrganismos, as enzimas e proteínas resultantes do seu metabolismo são empregadas na degradação de poluentes (GONÇALVES et al., 2013) . $\mathrm{O}$ aumento de atividades, que emitem poluentes em todo o mundo, desencadeia a necessidade de desenvolvimento de biotecnologias que sejam eficazes e ambientalmente seguras. A biorremediação surge como uma ferramenta para auxiliar na descontaminação de ambientes, utilizando organismos vivos (bactérias, fungos, algas ou plantas) ou seus subprodutos (ex: proteínas, enzimas, lipídios) para reduzir, eliminar, conter ou transformar contaminantes presentes no sedimento, na água e no ar (ADAMS et al., 2015; THAVASI et al., 2011) .

A aplicação de microrganismos imobilizados em biorremediação tem demonstrado ser mais eficaz na metabolização do poluente quando comparada com a de células livres. A presença da matriz impede o contato direto do poluente com o microrganismo, o que reduz os efeitos tóxicos para as células (ALVAREZ et al., 2017; DZIONEK et al., 2016) .

Tendo em vista a importância e eficácia da técnica de formulação de matriz para imobilização de bactérias e sua aplicação em biorremediação, este trabalho tem como objetivo realizar 
a prospecção de patentes para avaliar o estado da técnica no cenário atual e sua evolução ao longo dos anos.

\section{Metodologia}

Realizou-se a prospecção no banco de dados Banco Europeu de Patentes (Espacenet®) entre os meses de abril e maio de 2018. Utilizou-se como estratégia de busca as palavras-chave. Os códigos de classificação relacionados com o tema do trabalho foram encontrados através das seguintes palavras-chave: immobilization, bacterial immobilization e bioremediation. Utilizaram-se os operadores booleanos OR e AND para combinar as palavras e aumentar o número de códigos relacionados com o tema.

Devido à abrangência do tema e o propósito de realizar o levantamento de trabalhos relacionados à produção e formulação de matrizes poliméricas encapsulantes de bactérias com aplicação em biorremediação, não foi possível obter apenas um grupo que compilasse todas as áreas relacionadas ao tema. Portanto, selecionaram-se outros códigos de classificação para buscar informações, conforme descritos na Tabela 1.

Tabela 1 - Códigos de classificação selecionados e suas respectivas descrições

\begin{tabular}{|c|c|}
\hline Códigos & DESCRIÇÃo \\
\hline C02F2003/001 & Using granular carriers or supports for the microorganisms. \\
\hline $\mathrm{C} 02 \mathrm{~F} 3 / 108$ & Immobilising gels, polymers or the like. \\
\hline C02F3/102 & Permeable membranes. \\
\hline C12N11/04 & Entrapped within the carrier, e.g. gel, hollow fibre. \\
\hline C12N11/06 & Attached to the carrier via a bridging agent. \\
\hline C12N11/08 & Carrier being a synthetic polymer. \\
\hline C12N11/10 & Carrier being a carbohydrate. \\
\hline C12N11/14 & Enzymes or microbial cells being immobilised on or in an inorganic carrier. \\
\hline C12N11/16 & Enzymes or microbial cells being immobilised on or in a biological cell. \\
\hline C12N5/0012 & Cell encapsulation. \\
\hline C12N5/0677 & Three-dimensional culture, tissue culture or organ culture; encapsulated cells. \\
\hline B09 & $\begin{array}{l}\text { Disposal of solid waste; reclamation of contamined soil soil (treatment of waste water, } \\
\text { sewage or sludge C02F; treating radioactively contaminated solids G21F9/28). }\end{array}$ \\
\hline B09C & $\begin{array}{l}\text { Reclamation of contaminated soil (gatherers for removing stone or the like } \\
\text { from the soil A01B43/00; sterilising soil by steam A01G11/00; processes for } \\
\text { making harmful chemical substances harmless or less harmful by effecting } \\
\text { chemical change in the substance A62D3/00; separation in general. }\end{array}$ \\
\hline
\end{tabular}

Fonte: Elaborado pelos autores deste artigo (2018)

Após o mapeamento tecnológico, foram selecionados 13 códigos de classificação, que abordam patentes sobre microrganismos, imobilização e biorremediação. Os códigos foram combinados com a finalidade de realizar um mapeamento tecnológico na área de matrizes poliméricas, imobilização de células e biorremediação. Os arquivos resultantes da busca por 
patentes foram compactados e exportados para o aplicativo CSV - Comma Separated Values (Valores separados por vírgula) e posteriormente exportados para o software Microsoft Office Excel 2010 para visualização e tratamento dos dados.

Após analisar os dados, consideraram-se como indicadores: os códigos de classificação internacional, o ano de depósito, os inventores e o país de origem da patente. Os resultados foram apresentados em forma de gráficos.

\section{Resultados e Discussão}

O código C12N11/16 foi o que melhor contemplou o objetivo do trabalho (Quadro 1), pois contém 303 patentes depositadas, correspondendo a um total de 78 famílias de patentes (mesma patente depositada em diferentes países).

Quadro 1 - Escopo da busca de patentes

\begin{tabular}{|c|c|c|c|c|c|c|c|c|c|c|c|c|c|}
\hline 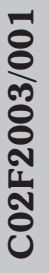 & 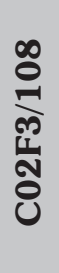 & 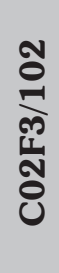 & 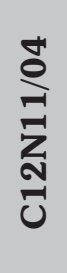 & 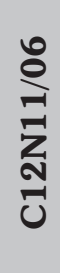 & 疍 & 音 & 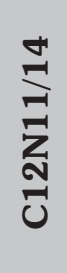 & 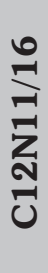 & 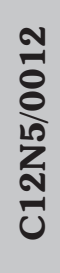 & 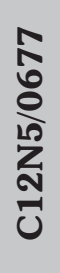 & ஓి & $\begin{array}{l}\text { O } \\
\text { Оे }\end{array}$ & $\begin{array}{l}\text { WORLD } \\
\text { WIDE } \\
\text { CPC }\end{array}$ \\
\hline \multirow[t]{13}{*}{$\mathrm{X}$} & & & & & & & & & & & & & 1,044 \\
\hline & $\mathrm{X}$ & & & & & & & & & & & & 729 \\
\hline & & $X$ & & & & & & & & & & & 391 \\
\hline & & & $\mathrm{X}$ & & & & & & & & & & 3,844 \\
\hline & & & & $X$ & & & & & & & & & 1,180 \\
\hline & & & & & $\mathrm{X}$ & & & & & & & & 5,792 \\
\hline & & & & & & $X$ & & & & & & & 2,869 \\
\hline & & & & & & & $\mathrm{X}$ & & & & & & 3,691 \\
\hline & & & & & & & & $\mathrm{X}$ & & & & & 303 \\
\hline & & & & & & & & & $\mathrm{X}$ & & & & 881 \\
\hline & & & & & & & & & & $\mathrm{X}$ & & & 901 \\
\hline & & & & & & & & & & & $X$ & & $>10,000$ \\
\hline & & & & & & & & & & & & $X$ & $>10,000$ \\
\hline $\mathrm{X}$ & & & $X$ & & & & & & & & & & 4 \\
\hline \multirow[t]{2}{*}{$\mathrm{X}$} & & & & & & & & $\mathrm{X}$ & & & & & 0 \\
\hline & & $X$ & & & $X$ & & & & & & & & 2 \\
\hline \multirow[t]{8}{*}{$\mathrm{X}$} & & & & & & & & $\mathrm{X}$ & & & & & 0 \\
\hline & & $\mathrm{X}$ & & & & & & $\mathrm{X}$ & & & & & 1 \\
\hline & & & & & & & & $\mathrm{X}$ & & & $\mathrm{X}$ & & 1 \\
\hline & & & & & & & & $\mathrm{X}$ & & & & $X$ & 1 \\
\hline & & $X$ & & & & $X$ & & & & & & & 0 \\
\hline & & $X$ & & & & & & & & & & $\mathrm{X}$ & 3 \\
\hline & & & & & & & & $\mathrm{X}$ & & $X$ & & & 0 \\
\hline & & & & & & & & $X$ & $X$ & & & & 0 \\
\hline
\end{tabular}




$\begin{array}{cccc}X & & X & 1 \\ X & X & & 124 \\ X & & X & 2\end{array}$

Fonte: Elaborado pelos autores deste artigo (2018)

A Figura 1 apresenta a evolução anual acumulada do depósito de patentes relacionadas à imobilização celular e biorremediação, com ênfase para a matriz polimérica e biorremediação por bactérias encapsuladas.

Figura 1 - Evolução anual do depósito de patentes entre os anos 1968 a 2018

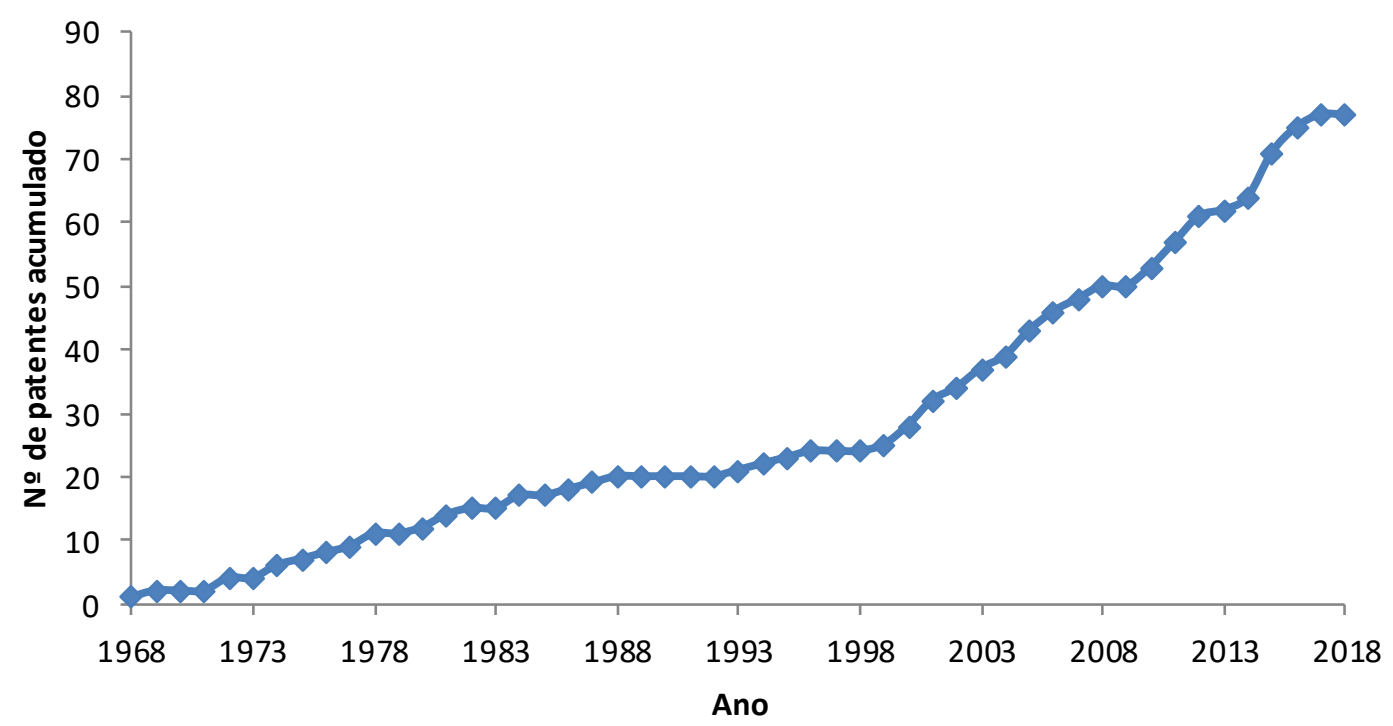

Fonte: Elaborado pelos autores deste artigo (2018)

Observou-se um aumento do número de patentes depositadas, sendo mais acentuado após o ano de 1998. Tecnologias para imobilização de bactérias e enzimas são relatadas desde a década de 60, sobretudo para o trânsito no corpo humano (JACK; ZAJIK, 1977; LINKO; LINKO, 1983).

O aumento observado a partir da década de 90 pode ser explicado pelos acidentes ambientais envolvendo petróleo, sobretudo o que ocorreu no Golfo Pérsico durante a guerra do Golfo, em 1991. O impacto ambiental resultante do derramamento do petróleo no mar foi avaliado por vários estudos que visam, sobretudo, a biorremediação (BAYAT et al., 2015; HASSANSHAHIAN et al., 2012).

Portanto, a utilização da técnica de imobilização de células aliada ao processo de biorremediação tornou-se um campo fértil para o desenvolvimento de patentes que busquem tecnologias para mitigar os impactos ambientais resultantes da cadeia produtiva do petróleo e outros poluentes.

A partir do ano de 2018, observa-se uma queda no número de depósitos, que pode ser justificada através do período de sigilo de dezoito meses das patentes, portanto, o decréscimo não é justificado pela queda no número de depósitos.

A Figura 2 apresenta os dados obtidos a partir da busca sobre os países de origem do depositante, nos quais foram desenvolvidas as tecnologias patenteadas. Verifica-se que não 
existe um elevado número de patentes depositadas em apenas um país, pois os depósitos são distribuídos, sobretudo, em três países: Estados Unidos, Japão e China. O maior número de patentes depositadas nesses países pode ser justificado por serem grandes potências tecnológicas.

Os Estados Unidos foi o país a apresentar o maior número de patentes (22), seguido pelo Japão, que apresentou nove patentes e a China, em $3^{\circ}$ lugar, com cinco patentes. O Brasil encontra-se em $6^{\circ}$ lugar, juntamente com a República da Coreia, possuindo apenas três patentes relacionadas à tecnologia pesquisada. Outros países apresentaram apenas uma patente, a exemplo da Rússia e Espanha (dados não mostrados).

Figura 2 - Número de patentes depositadas por país

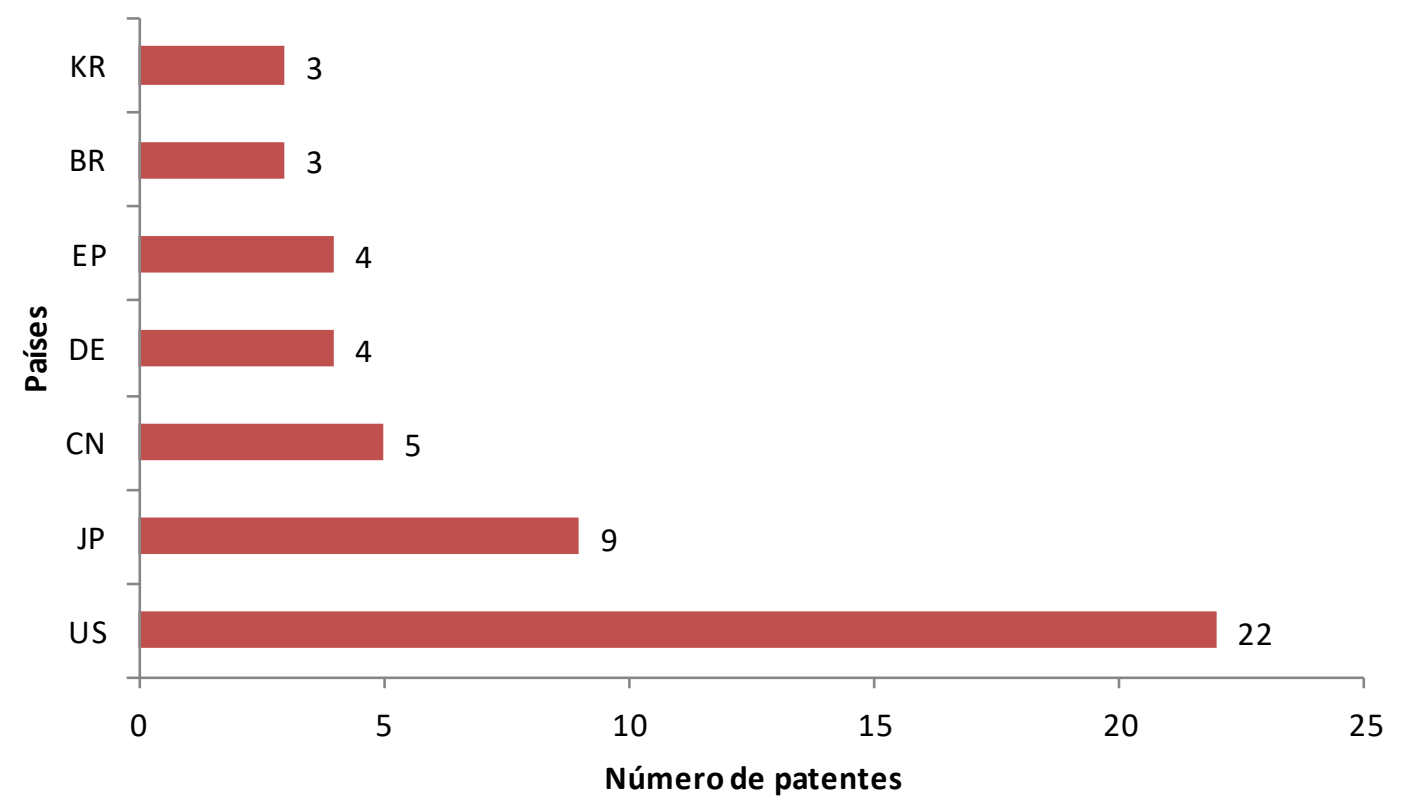

Fonte: Elaborado pelos autores deste artigo (2018)

Os Estados Unidos, Japão e China são os países com expressivo volume de publicação científica sobre imobilização de células, sendo a China um dos países a apresentar maior número de publicações sobre a área de biorremediação. Portanto, os números de patentes depositadas nesses países refletem o cenário científico local.

No Brasil, além de o país possuir apenas três patentes, as tecnologias registradas referem-se a métodos de produção enzimática e otimização metabólica, são elas: BR112017013748, BR112015015775 e BR112014029953. Todas registradas no Brasil, porém os países de origem dos inventores são Estados Unidos e Israel.

A BR112017013748, depositada em 13 de março de 2018, refere-se à tecnologia para produção de dinamina, através de um microrganismo geneticamente modificado. As dinaminas são produzidas por fermentação na qual haverá a formação de dinaminas carbonato, bicarbonato, bis-bicarbonato e/ou carbamato ou biscarbamato. Após a formação das dinaminas carbonatadas, há a conversão em base livre e dióxido de carbono e isolamento das dinaminas livres. As dinaminas serão empregadas para minimizar a formação indesejável de sal que ocorre como resultado do emprego de ácidos e bases no processo de produção das dinaminas.

A BR112015015775, depositada em 11 de julho de 2017, refere-se à preparação enzimática para uso na degradação de celulose. A hidrólise da celulose é desafiadora, pois apenas 
alguns microrganismos possuem esta capacidade, o que torna o processo de degradação da biomassa vegetal demorado e dispendioso. Para reduzir o custo, a tecnologia propõe o cultivo de um microrganismo com capacidade para produzir celulas cultivado em biomassa celulósica, na qual o produto resultante dessa biomassa é coletado e usado para degradar celulose, sem qualquer tratamento prévio desse substrato.

A BR112014029953, depositada em 27 de junho de 2017, refere-se à produção eficiente de grandes quantidades de bactéria do gênero Methylobacterium. Metilobactérias constituem um conjunto de bactérias que metabolizam compostos orgânicos de carbono como metanol. Produtos do cultivo de metilobactérias podem ser empregados em plantas ou partes de plantas, em biorremediação, e na produção de proteínas recombinantes.

O mapeamento patentário realizado por Macedo et al. (2015) no período de 1982 a 2012 revelou que, assim como observado para imobilização celular, os Estados Unidos, a China e o Japão são os países a apresentar o maior número de patentes publicadas relacionadas às tecnologias na área de biorremediação. Os dados obtidos por Macedo et al. (2015) indicam que o Brasil não aparece entre os dez principais países depositantes.

A Figura 3 apresenta a quantidade percentual dos detentores de patentes distribuídos em Academias (universidades e institutos), Empresas e Pessoa Física. Patentes depositadas por pessoa física representam a maior parte dos detentores de patentes (45\%).

Figura 3 - Percentual dos detentores de patentes relacionadas à tecnologia pesquisada

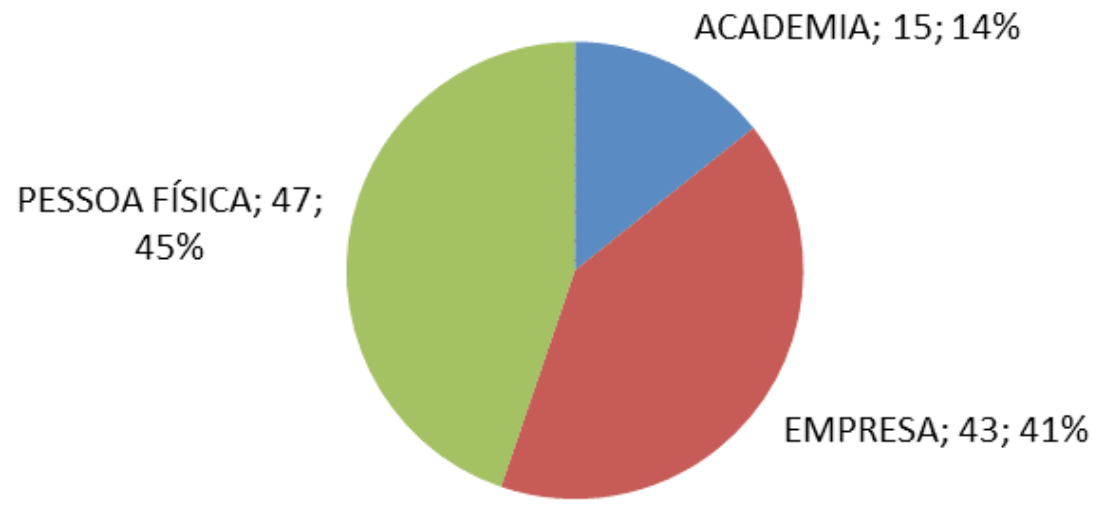

Fonte: Elaborado pelos autores deste artigo (2018)

As empresas detêm $41 \%$ das patentes depositadas sobre imobilização de células ou enzimas e uso em biorremediação, sendo essas empresas, sobretudo, do ramo de tecnologias ambientais, cosmético e saúde. Esse valor reflete o cenário das pesquisas em biotecnologia, que demandam recursos financeiros. Universidades e institutos possuem apenas $14 \%$ do total de patentes pesquisadas.

Os códigos que mais apresentaram patentes relacionadas ao tema do trabalho estão descritos na Figura 4. Os códigos são subdivisões do código C12N, o qual refere-se a microrganismos ou enzimas, propagação, preservação ou manutenção de microrganismos e mutação ou engenharia genética; meio de cultura. Observa-se que o código C12N11/16, relacionado à imobilização de enzimas ou células microbianas, conforme descrito na Tabela 1 , foi o mais empregado nas patentes. 
Os outros três códigos resultantes da busca não possuem relação direta com imobilização, mas com produção de enzimas e cultivo de microrganismos. O código C12N15/09 agrupa tecnologia referente a DNA-recombinante. Apesar de ser um código que está incluído no C12N, não possui relação direta com o tema da tecnologia pesquisada. O código C12N1/20 refere-se a tecnologias sobre bactérias e meios de cultura, sendo, portanto, relacionado com a imobilização de células. O código $\mathrm{C} 12 \mathrm{~N} 1 / 00$ refere-se a microrganismos, processo de propagação, manutenção ou preservação de microrganismos ou composições, processo de preparação ou isolamento de uma composição contendo microrganismos e meio de cultura. Portanto, esse código é mais amplo e engloba o C12N1/20.

Os códigos de classificação resultantes do levantamento sobre a tecnologia abordada refletem o quão abrangente é o tema de imobilização, podendo envolver bactérias e seu cultivo, enzimas, composição química de membranas imobilizantes, biologia molecular e biorremediação.

Figura 4 - Número de patentes por código de classificação

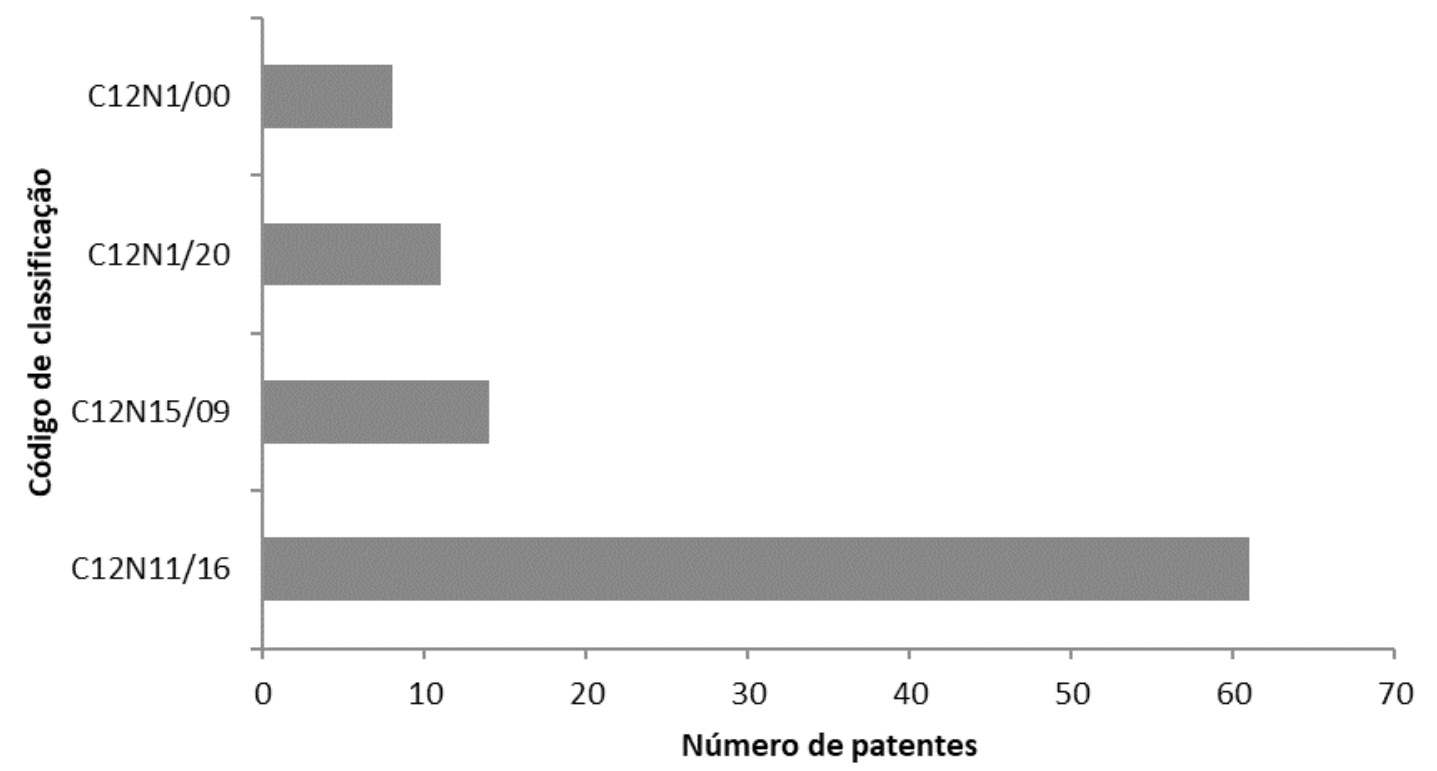

Fonte: Elaborado pelos autores deste artigo (2018)

Os depósitos de patentes relacionados à imobilização de bactérias em matriz polimérica para aplicação em biorremediação ainda são escassos. A prospecção demonstrou que há muitas patentes relacionadas ao desenvolvimento de uma matriz para imobilização, assim como diferentes técnicas para imobilização de células e biomoléculas, sendo estas patentes pouco voltadas para a biorremediação. Algumas delas são descritas a seguir:

US2017321207, depositada pela empresa BIORIGHT WORLDWIDE COMPANY LTD [VG], refere-se a um dispositivo e um método para a preparação de proteínas imobilizadas, enzimas ou células num transportador para produção em escala industrial. O dispositivo foi desenvolvido para superar as deficiências das técnicas existentes para imobilização, e para tanto compreende uma correia transportadora de carreador imobilizante, componentes para pulverização e componente espremedor que remove o excesso de líquido na superfície do carreador. $\mathrm{O}$ dispositivo visa, portanto, melhorar o processo de obtenção de células, proteínas ou enzimas imobilizadas.

US4722898, depositada pela empresa MINNESOTA MINING \& MFG [US], refere-se a uma matriz de fibrila de politetrafluoroetileno (PTFE) para imobilização de células para aplicação como 
catalisadores industriais em síntese orgânica, fermentação e remoção de poluentes químicos. A patente descreve a formulação de uma matriz de politetrafluoroetileno fibrilada sob a forma de películas microporosas, folhas compósitas, fibras, grânulos e semelhantes. O funcionamento da matriz ocorre de tal forma que as células se mantêm viáveis e metabolicamente ativas, de modo que os produtos residuais do metabolismo (que podem ser úteis para o comércio) são continuamente removidos.

CN106400466, depositada pela HENAN UNIVERSITY OF TECHNOLOGY, refere-se a um material transportador e imobilizante preparado a partir de fibras de carbono por um método modificado. As matrizes de fibra de carbono existentes possuem uma camada de cola orgânica, o que aumenta a inércia superficial da fibra de carbono. A fibra de carbono modificada permite maior adesão ao material a ser imobilizado, pouco tempo para confecção da matriz e menor potencial de poluição ambiental. Os autores relatam que a matriz de fibra de carbono modificada reteve $60-80 \%$ da atividade da xilase imobilizada.

W095/08513, depositada pela empresa SBP TECHNOLOGIES, INC. [US], refere-se à formulação de uma matriz contendo aditivo para imobilização de microrganismos e utilização no controle da poluição. A matriz de encapsulamento ou imobilização é constituída por PVA, vermiculita e PU. A imobilização de bactéria do gênero Pseudomonas na matriz contendo os aditivos permitiu um aumento na degradação de hidrocarbonetos policíclicos aromáticos de alto peso molecular. De acordo com os autores, a matriz é um método que pode ser empregado em biorremediação de solo, ar ou água contaminados.

\section{Considerações Finais}

O presente trabalho retrata o cenário referente a invenções no contexto de formulação $e$ produção de matriz polimérica, focando no potencial para imobilização de células bacterianas, aliada à aplicabilidade na descontaminação de ambientes por técnicas de biorremediação.

O número de patentes relacionadas à imobilização de células e enzimas para uso em biorremediação tem registro desde 1968 (uma patente), apresentando considerável acréscimo até 2018 (77 patentes). Portanto, a área de imobilização celular é um campo promissor para estudos que visem invenções tecnológicas.

Dentre as patentes pesquisadas, grandes potências mundiais como os Estados Unidos (22 patentes), Japão (nove patentes) e China (cinco patentes) são os países que possuem os maiores números de patentes depositadas, sendo os Estados Unidos o maior deles. $\mathrm{O}$ que reflete a necessidade de mais estudos sobre o tema no Brasil. A falta de investimento e logística das universidades e institutos comparados às empresas acarretam no menor percentual de depósito de patentes pela academia, aliado à transferência de propriedade intelectual desta para as empresas.

Diante do cenário mundial representado neste estudo de prospecção, conclui-se que pesquisas desenvolvidas e patenteadas com matrizes poliméricas imobilizantes de células bacterianas para aplicação em biorremediação apresentam potencial exploratório, visto que estudos relacionados com o tema ainda são escassos. 


\section{Referências}

ADAMS, G. O.; FUFEYIN, P. T.; OKORO, S. E. Bioremediation, Biostimulation and Bioaugmention: A Review. International Journal of Environmental Bioremediation \& Biodegradation, v. 3, n. 1, p. 28-39, mar. 2015.

ALVAREZ, A.; SAEZ, J. M.; COSTA, J. S. D.; COLIN, V. L.; FUENTES, M. S.; CUOZZO, S. A.; BENIMELI, C. S.; POLTI, M. A.; AMOROSO, M. J. Actinobacteria: Current research and perspectives for bioremediation of pesticides and heavy metals. Chemosphere, v. 166, p. 41-62, jan. 2017.

BAYAT, Z.; HASSANSHAHIAN, M.; CAPPELLO, S. Immobilization of Microbes for Bioremediation of Crude Oil Polluted Environments: A Mini Review. The open microbiology journal, v. 9, p. 48-54, jul. 2015.

BIORIGHT WORLDWIDE COMPANY LTD (Estados Unidos). Cheung Chung Hong [CN]; Wang Jun [CN]; Chen Junming [CN]; Wang Guilin [CN]. Device and a Method for Immobilization of Proteins, Enzymes or Cells. US2017321207, 09 nov. 2017. Disponível em: <https://worldwide. espacenet.com/>. Acesso em: 20 abr. 2018.

DESIGNER ENERGY LTD [IL]. Alon Karpol [IL]; Ely Morag [IL]; Michael Anbar [IL]; Tal Barak [IL]. Highly potent cellulolytic enzyme preparations and processes for producing same. BR112015015775, 11 set. 2017. Disponível em: <https://worldwide.espacenet.com/>. Acesso em: 20 abr. 2018.

DZIONEK, A.; WOJCIESZYNSKA, D.; GUZIK, U. Natural carriers in bioremediation: A review. Electronic Journal of Biotechnology, v. 23, p. 28-36, sept. 2016.

ELNASHAR, M. M. M. Review Article: Immobilized Molecules Using Biomaterials and Nanobiotechnology. Journal of Biomaterials and Nanobiotechnology, v. 1, n. 1, p. 61-77, oct. 2010.

ESPACENET [Base de dados - Internet]. European Patent Office; 2018. Disponível em: < https:// worldwide.espacenet.com/> Acesso em 25 abril. 2018.

GENOMATIC INC [US], Cara Tracewell [US]; Connor J Galleher [US]; Lauri H Suominen [US]; Mark J Burk [US]; Michael Japs [US]. Method of producing \& processing diamines.

BR112017013748, 13 mar. 2013. Disponível em: < https://worldwide.espacenet.com/>. Acesso em: 20 abr. 2018.

GONÇALVES, O.; CERQUEIRA, G. S.; QUINTELLA, C. M. Biorremediação microbiológica de áreas impactadas com petróleo através do uso de fungos e subprodutos do biodiesel de mamona: mapeamento patentário. Cadernos de Prospecção, v. 6, n. 2, p. 144-151, 2013.

HASSANSHAHIAN, M.; EMTIAZI, G.; CAPPELLO, S. Isolation and characterization of crude-oildegrading bacteria from the Persian Gulf and the Caspian Sea. Marine Pollution Bulletin, v. 64, p. 7 - 12, jan. 2012.

HENAN UNIVERSITY OF TECHNOLOGY (China). Wang Le; Wei Qixian; Hui Ming; Wu Dapeng; Shen Yan. Immobilizing carrier material prepared from carbon fibers by modification method. CN106400466, 15 fev. 2017. Disponível em: < https://worldwide.espacenet.com/> . Acesso em: 20 abr. 2018.

JACK, T. R.; ZAJIK, J. E. The immobilisation of whole cells. Advances in Biochemical

Engineering, v. 5, p. 125- 145, sept. 1977. 
KAREL, S. F.; LIBICKI, S. B.; ROBERTSON, C. R. The immobilization of whole cells: engineering principles. Chemical Engineering Science, v. 40, n. 8, p. 1.321-1.354, 1985.

LINKO P.; LINKO Y. Y. Application of immobilized microbial cells. In: Lemuel BW, Ichiro C (eds) Applied biochemistry and bioengineering. Academic press, New York, v. 4, p 97, 1983.

MACEDO, C.; ANGELI, R.; OLIVEIRA, S. D.; CARMO, F. L. Mapeamento tecnológico dos processos de biorremediação: uma análise no contexto da biotecnologia sustentável. Cadernos de Prospecção, v. 8, n. 3, p. 450-458, 2015.

MARTINS, S. C. S.; MARTINS, C. M.; FIÚZA, L. M. C. G.; SANTAELLA, S. T. Immobilization of microbial cells: A promising tool for treatment of toxic pollutants in industrial wastewater. African Journal of Biotechnology, v.12, p. 4.412-4.418, july 2013.

MINNESOTA MINING \& MFG (Estados Unidos). Errede Louis A [US]; Hunt George R [US]. Immobilization of biological cells in polytetrafluoroethylene matrix. US4722898, $02 \mathrm{fev}$. 1988. Disponível em: <https://worldwide.espacenet.com/>. Acesso em: 20 abr. 2018.

NEWLEAF SYMBIOTICS INC [US]. Gregg Bogosian [US], Microbial Fermentation Methods and Compositions. BR112014029953, 27 jun. 2018. Disponível em: < https://worldwide.espacenet. com/> . Acesso em: 20 abr. 2018.

ORIVE, G.; HERNÁNDEZ R. M.; GASCÓN, A. R.; CALAFIORE, R.; CHANG, T. M. S.; VOS, P.; HORTELANO, G.; HUNKELER, D.; LACÍR, I. History, challenges and perspectives of cell microencapsulation. Trends in Biotechnology, v. 22, n. 2, p. 87-92, feb. 2004.

PEINADO, R. A.; MORENO, J. J.; MAESTRE, O.; MAURICIO, J. C. Use of a novel immobilization yeast system for winemaking. Biotechnology Letters, v. 27, n. 18, p. 1.421-1.424, sep. 2005.

SBP TECHNOLOGIES, INC. [US/US] (Estados Unidos). Lin Jian-Er; Mueller James G; Pritchard $\mathrm{P}$ Hap. Biocomposite comprising a microorganism and an additive in a formulation matrix for bioremediation and pollution control. WO9508513, 30 mar. 1995. Disponível em: < https:// worldwide.espacenet.com/ > . Acesso em: 20 abr. 2018.

THAVASI, R.; JAYALAKSHMI, S.; BANAT, I. M. Effect of biosurfactant and fertilizer on biodegradation of crude oil by marine isolates of Bacillus megaterium, Corynebacterium kutscheri and Pseudomonas aeruginosa. Bioresource Technology, v. 102, n. 2, p. 772-778, 2011.

WASI, S.; TABREZ, S.; AHMAD, M. Use of Pseudomonas spp. for the bioremediation of environmental pollutants: a review. Environmental Monitoring and Assessment, v. 185, n. 10, p. 8.147-8.155, oct. 2013.

\section{Sobre os autores}

\section{Carla Jaqueline Silva Sampaio}

E-mail: sampaiosjcarla@gmail.com

Lincenciada em Ciências Biológicas (Universidade Federal da Bahia, 2013). Mestre em Biotecnologia (Universidade Federal da Bahia, 2015).

Endereço Profissional: Laboratório de Microbiologia Aplicada e Bioprospecção, Instituto de Ciências da Saúde, Departamento de Biointeração, Universidade Federal da Bahia (UFBA), Campus Canela, CEP: 40110-100, Salvador-Bahia, Brasil. 


\section{Cristina Maria Quintella}

E-mail: cris5000tina@gmail.com

Bacharel em Física (Universidade Federal do Rio de Janeiro, 1983). Mestra em Físico-Química (Instituto de Química da Universidade Federal do Rio de Janeiro, 1985). Doutora interdisciplinar em Ciências Moleculares (University of Sussex, UK, 1993).

Endereço Profissional: Laboratório de Cinética e Dinâmica Molecular, Instituto de Química, Departamento de Química Geral e Inorgânica, Universidade Federal da Bahia (UFBA), Campus Ondina, CEP: 40170-290, Salvador-BA.

\section{Milton Ricardo de Abreu Roque}

E-mail: milton.roque@ufba.br

Graduado em Ciências Biológicas (Universidade Católica de Campinas, 1990). Mestre em Agronomia (Universidade Estadual Paulista Júlio de Mesquita Filho, 1993). Doutor em Ciências Biológicas (Universidade Estadual Paulista Júlio de Mesquita Filho, 2000).

Endereço Profissional: Laboratório de Microbiologia Aplicada e Bioprospecção, Instituto de Ciências da Saúde, Departamento de Biointeração, Universidade Federal da Bahia (UFBA), Campus Canela, CEP: 40110-100, Salvador-BA. 